\title{
Experiments on exploring and monitoring landslip-mass using geoelectric resistivity observations*
}

\author{
AN Jin-zhen ${ }^{1), "}$ (安金珍) ZHOU Ping-gen ${ }^{2)}$ (周平根) MA Mai-ning ${ }^{3)}$ (马麦宁) \\ CHEN Feng ${ }^{1)}$ (陈 峰) DONG Ying ${ }^{2)}$ (董颖) ZHONG Pei-lin ${ }^{4)}$ (钟沛林) \\ 1) School of Earth and Space Sciences, Peking University, Beijing 100871, China \\ 2) China Institute of Geological Environment Monitoring, Beijing 100081, China \\ 3) Graduate University of the Chinese Academy of Sciences, Beijing 100049, China \\ 4) General Station of Geological Environment Monitoring of Sichuan Province, Chengdu 610000, China
}

\begin{abstract}
In the experiments, a high-density resistivity method is used to explore the electric structure of landslip mass, and a resistivity-changing anisotropy method is used to monitor the orientation and speed of main fracture extending of landslip mass. The results are as follows. (1) The exploring experiments have verified a part of creep deformation borderline, the depth and thickness of groundwater horizon, and the property of superstrata in the landslip mass investigated formerly, which have proved that the landslip belts contain rich groundwater; (2) The main fracture extending orientation inferred from the resistivity-changing anisotropy accords with the strike of fracture belt of landslip mass deduced from GPS displacement. Moreover, the changing rates of resistivity-changing anisotropy coefficient matches with the changing speeds of deep displacement of landslip mass were measured by suing clinometer in the borehole.
\end{abstract}

Key words: geoelectric resistivity; resistivity anisotropy; geologic hazard; landslip CLC number: P315.72 2 Document code: A

\section{Introduction}

The transition of rock mass from steady to non-steady state may bring about many hazards of geology and engineering geology, such as earthquake, landslip, dilapidation, slip of manual slope and batholith, collapse of underground engineering and mine, and earth-surface landfall, etc, which may bring about a disaster to the human lives and estates. The hazards have one common characteristic, namely, new cracks may produce inside the rock mass or old cracks may extend in the generating and developing courses of hazards. Therefore, many studies have been carried out for indoor simulation experiments on the concomitant resistivity variation state and anisotropy in the processes of new crack generation or old crack extension. (QIAN et al, 1989; ZHANG, 1981; ZHAO et al, 1983; ZHANG and LU 1983; ZHANG et al, 1985; CHEN et al, 1987; LU et al, 1988, 1990; AN et al, 1996; CHEN et al, 2000, 2003a, 2003b). The experiments have found, in the

\footnotetext{
* Received 2007-12-10; accepted in revised form 2008-04-10.

Foundation item: National Natural Science Foundation of China (40521002 and 40774047).

^ Author for correspondence: ajz@pku.edu.cn
} 
processes of new crack generation or old crack extension, not only the concomitant shape variation of apparent resistivity, but also a closer relation to the apparent resistivity-changing anisotropy. To verify the indoor experiments, field tests are made by using resistivity-changing anisotropy method to monitor landslip mass.

There are examples in exploring and monitoring geologic structures of hazards of landslip, dam, groundwater and geologic engineering, etc, by using geoelectric resistivity (TANG, 1999; Rein et al, 2004; Sjödahl et al, 2005; Polder, 2001), especially in forecasting rock-mass destabilization of coalfield. Delightful results have been achieved in the research (ZOU et al, 2003). Along with the appearance of high-density resistivity method, geoelectric resistivity will draw more and more attentions in studies.

A new kind of experiment is introduced in the paper, which can not only explore geologic structures of geologic hazard mass, but also monitor the catastrophic precursors of geologic hazard mass. The experiment, exploring the electric structure of landslip mass by a traditional high-density resistivity method and monitoring the extending orientation and speed of main fracture of landslip mass by a new method of resistivity-changing anisotropy, combines the traditional method with the new one, and exploration with monitoring.

\section{Geological surroundings and developing characteristics of land- slide area}

The experiment site is the landslide mass located on the left bank of Longxi River (Figure 1). The geological structure in this area is mainly folds. The northwestern part is subject to the Longmenshan geological structural zone and the lineament is NE-SW; while the southeastern part is restricted by the Sichuan-Yunnan geological structural zone and the lineament is N-S.

The climate in this area belongs to the sub-tropical wet monsoonal climate with not very cold winters and not very hot summers. The temperature increases fast in the spring and the temperature range is large. The rain season is the hot season and the precipitation is concentrated from June to September. The annual precipitation is about $1732 \mathrm{~mm}$ and the average temperature is about $16.2^{\circ} \mathrm{C}$.

Xiakou landslide is located on a revived landslide that can be divided into three parts: paleo-landslide, old landslide, and new landslide. The Longxi River valley appears to be gorge in the Xiakou section. The left bank is steep cliff and the right bank is gentle slope because of landslide. The landslide area preserves a complete couch-like landform consisting of three platforms. The first platform is $59 \mathrm{~m}$ high above river level. This platform is well conserved on the left of the landslide,

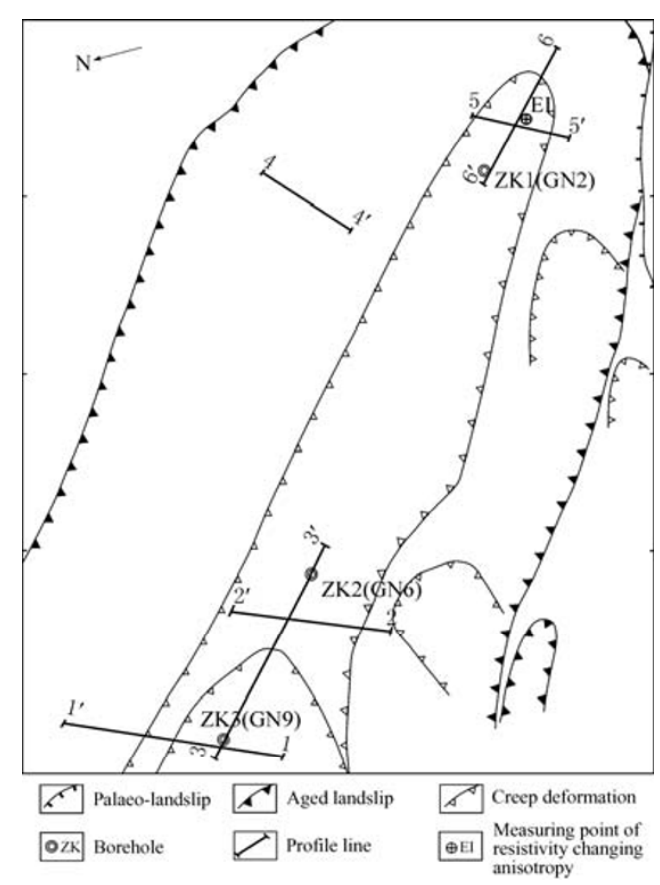

Figure 1 Exploring and monitoring deployment of the Xiakou landslip mass 
while it evolves into a new landslide on the right side. The second platform is about $119 \mathrm{~m}$ high above river level, which is basically well preserved except new landslide and gully in some parts. The third platform is about $177 \mathrm{~m}$ high above river level and it is well preserved. The gradient of three platforms is less than $10^{\circ}$; the gradient of the overall slope is about $20^{\circ}$, and the gradient of the ridges is about $30^{\circ}$.

Xiakou landslide consists of inter-bedded hard and soft rock layers and the rock tip is the same as the slope tip. The lower part of the landslide mass is inter-bedded feldspar-quartz fine sandstone and mudstone and the upper part is mudstone and siltstone, which are soft and liable to be weathered. The landslide mass is composed of clay and detritus with different weathering levels, and the slide surface forms between different weathering levels. The profile of landslide is concave-convex, i.e., the upper part is concave and the lower part is convex. According to the borehole data, the slide surface is a polygonal line, i.e., steep in the upper part and gentle in the lower part. Longxi River flows through the landslide foot from the north to the south and the flow gradient is about $24.5 \%$. The river is very torrential, eroding the landslide foot badly.

The revived landslide, with a volume of $2600000 \mathrm{~m}^{3}$, is a pushing type. A landslide occurred from July to August, 1981, destroyed a large number of houses, farmlands, highway, and trenches on the slope. The front shear zone in an upheaval arcuate shape, stretching from the middle of the river, consists of red clay under severe compression and brecciated granodiorite.

The bedrock of the landslide area is Cretaceous sandstone-mudstone. The landslide material is purplish red clay and rock fragments. The slide surface is between the bed rock and the sediments, which contains rich groundwater. The landslide keeps moving slowly, pushing the $60 \mathrm{~m}$ highway to deform seriously little by little. Several cracks in the highway are $0.2 \sim 0.3 \mathrm{~m}$ in width and rock blocks often fall onto the highway.

Groundwater plays an important role in developing landslide. There are two sources of groundwater: (1) precipitation infiltration and groundwater in the cracks of bedrock; (2) the seepage of seasonal irrigation. The springs in the front of the landslide keep flowing through the year.

\section{Test methods}

\subsection{Tests of exploring electric structure of landslip mass}

In the tests, we adopt the Wenner method of high-density geoelectric resistivity (Figure 1). Six profiles are measured in the upper and lower parts of the landslip mass and five of them span the borderline of creep deformation of landslip mass. The longest profile is $132 \mathrm{~m}$.

\subsection{Tests of monitoring resistivity-changing anisotropy}

In the tests, we adopt the method of four-electrode symmetrical arrangement and the manner of homocentric arrangement for the measuring points of large and small electric polar distances (Figure 2). The $A-B$ electrodes spacing is $28 \mathrm{~m}$ for the measuring point of large polar distances,

Table 1 Arrays and measuring-function combinations

\begin{tabular}{|c|c|c|c|c|c|c|c|c|c|}
\hline \multirow[t]{2}{*}{ Array No. } & \multicolumn{4}{|c|}{$\begin{array}{l}\text { Measuring points of anisotropy with small } \\
\text { electric polar distance }\end{array}$} & \multirow[t]{2}{*}{ Array No. } & \multicolumn{4}{|c|}{$\begin{array}{l}\text { Measuring points of anisotropy with large } \\
\text { electric polar distance }\end{array}$} \\
\hline & $A$ & $B$ & $M$ & $N$ & & $A$ & $B$ & $M$ & $N$ \\
\hline 1 & 2 & 5 & 3 & 4 & 5 & 1 & 6 & 3 & 4 \\
\hline 2 & 8 & 11 & 9 & 10 & 6 & 7 & 12 & 9 & 10 \\
\hline 3 & 14 & 17 & 15 & 16 & 7 & 13 & 18 & 15 & 16 \\
\hline 4 & 20 & 23 & 21 & 22 & 8 & 19 & 24 & 21 & 22 \\
\hline
\end{tabular}

Note: The array No. of measuring points of anisotropy with large and small polar distance are correspondent with that in Figure 2. 
while the $A-B$ electrodes spacing is $18 \mathrm{~m}$ for the point of small polar distances. The arrays and measuring-function combinations of large and small polar distances are shown in Table 1. The measuring points are selected in the upper part of the landslip mass near the corner of the creep deformation belt (Figure 1). Copper electrodes of high-density resistivity are adopted for the measuring points. We enlace the connected lug of the electrode wire and the measuring cable with a plastic bag and bury them underground in a shallow depth. The measuring cable is placed on the ground and pulled into room in measurement (about $150 \mathrm{~m}$ in distance). The measuring instrument is a special resistivity-changing anisotropy measuring device produced by Chongqing Geological Instrument Factory, whose indexes are the same as those of

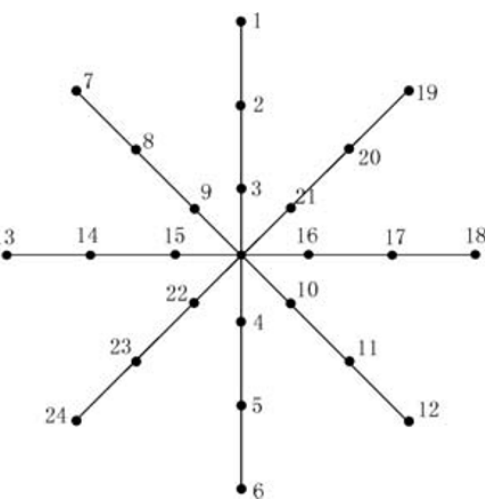

Figure 2 Arrangement of electrodes for monitoring resistivity-changing anisotropy the high-density geoelectric resistivity measuring instrument produced by that factory, except dividing the input impedance into $30 \mathrm{M} \Omega$ and $120 \mathrm{M} \Omega$, and the $A-B$ electrode current into $0 \sim 5 \mathrm{~A}$ and $0 \sim 4 \mathrm{~mA}$. Direct-current accumulators are used for the $A-B$ electrodes in the measurement. The monitoring tests started from August 16, 2002 and ended in early January, 2003.

\section{Result, explanation and discussion of tests}

\subsection{Tests of exploring electric structure}

In the tests, four out of five profiles $\left(1-1^{\prime}, 2-2^{\prime}, 3-3^{\prime}, 5-5^{\prime}, 6-6^{\prime}\right)$ across the borderline of creep deformation of landslip mass can reflect the borderline. Two profiles correspond well to the borderline location of creep deformation obtained in the previous investigation, while the other two profiles differ from the former borderline location. Figure $3 \mathrm{a}$ is a result imaging of profile 5 that is located in the upper part of landslip mass in an assuming NNE-SSW strike from the north to the south. It is apparent from Figure $3 \mathrm{a}$ there is a discontinuous resistive formation with a thickness of about 4 $m$ in the upper part of profile. However, the south end is not the same as the north end, for there is no resistive formation in a distance of a few meters in the south end and this boundary corresponds to the borderline location of creep deformation of landslip mass (see Figure 3a and Figure 1). In the lower part of profile, there are two low-resistivity zones. The one in the lowest part has a resistivity value close to that of water.

Figure $3 \mathrm{~b}$ is a result imaging of profile 2 that is located in the middle-lower part of landslip mass near the ZK2 borehole in an assuming S-N strike from the south to the north. We can see from the figure there is a resistive formation of $4 \mathrm{~m}$ thick in a length of more than ten meters in the south end. However, the resistive formation is not evident towards the north and forms a clear boundary here, which is close to the borderline location of creep deformation of landslip mass (see Figure $3 \mathrm{~b}$ and Figure 1). There is a continuous resistive formation of about $6 \mathrm{~m}$ thick in the upper part on the north of profile and a low resistivity zone, whose resistivity value is similar to that of water, in the lower part. It is close to the groundwater table measured at ZK2 borehole near the array (see Figure 4a), which verifies that the landslip belts contain rich groundwater. These results are of great significance to the previous monitoring work of landslip. 

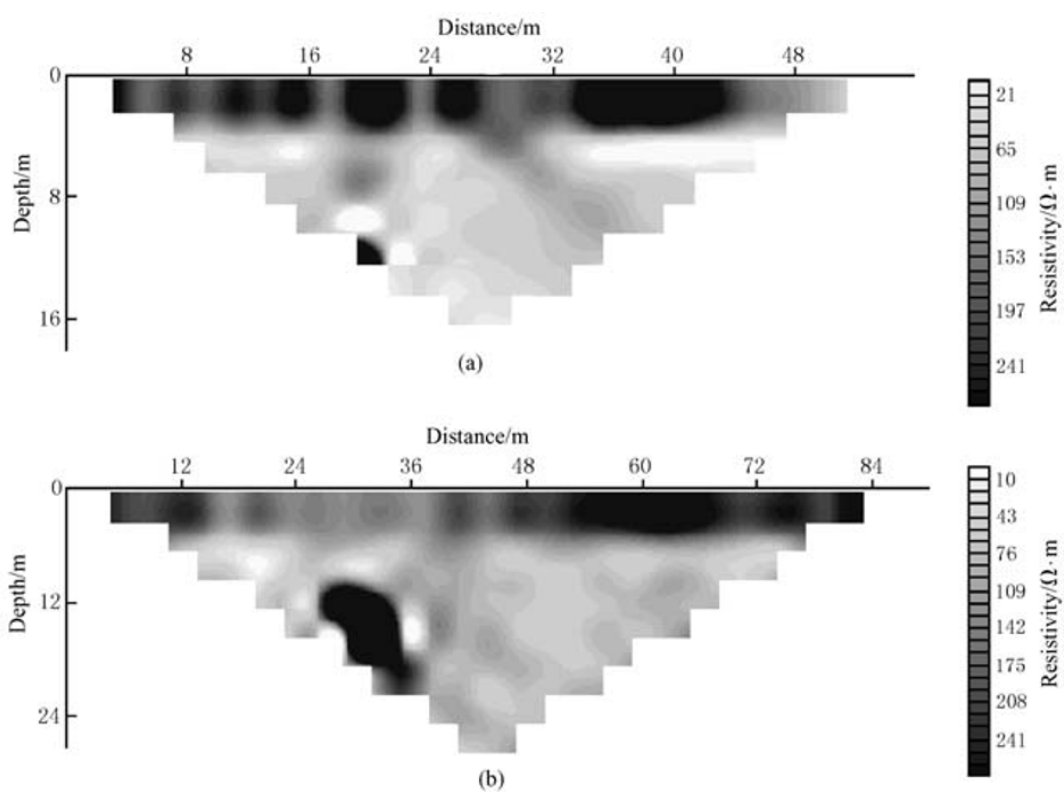

Figure 3 Diagram of exploring electric property structure in landslip mass (a) Result imaging of profile 5; (b) Result imaging of profile 2
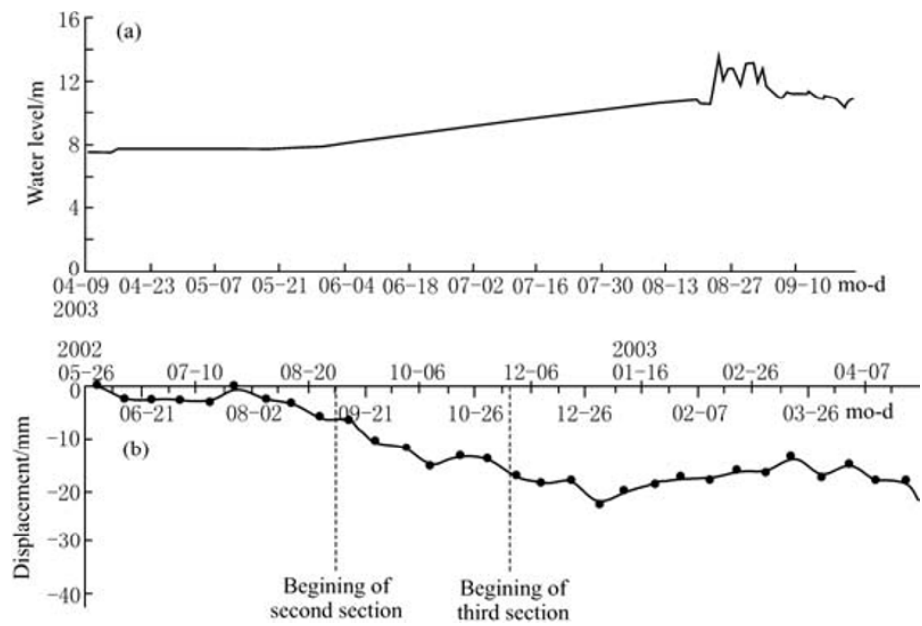

Figure 4 Variation of groundwater level and deep displacement within boreholes

(a) Variation of groundwater level within borehole ZK2; (b) Variation of deep displacement within boreholes ZK1. Beginning of second section (August 25, 2002), Beginning of third section (November 10, 2002)

\subsection{Tests of monitoring resistivity-changing anisotropy}

According to the basic monitoring conditions, data processing can be divided into three segments. The first segment is August 16 25, 2002, which is a debugging monitoring phase and the observed data are not used in data processing except two used as cardinal number. The second segment is from August 25 to November 9, 2002. The data in the former half of this segment (August 25 to September 25) are continuous and applicable, while the data in the latter half of the segment (September 26 to November 9) are not reliable and cannot be used in data processing, for the 
arrays are buried in a shallow depth in the mountain and some parts are trampled by grazing cattle and sheep. The third segment is from November 10, 2002 to January 2003. The data in the former half of this segment (November 10 28) are measured in the resuming monitoring and they are continuous and applicable, while the data in the latter half (November 29, 2002 to January 2003) are inaccurate and cannot be used in data processing for the same reason as the second segment.

Figure 5 shows the results of resistivity-changing anisotropy in the principal-axis directions for the arrays of small polar distance in the former stage of second and third segments (the physical quantity of polar axes in the figure is the square of apparent anisotropy coefficient $\left(\lambda^{*}\right)$, which has magnitude only but no unit). We can see from the figure that the four principal-axis directions of resistivity-changing anisotropy are basically identical (see CHEN et al, 2000 for the principles and data processing of the method). The principal-axis angles of resistivity-changing anisotropy in the third segment change evidently as compared to the second segment, which shows that the monitoring point has an anisotropic change within the exploring area, namely, new cracks have generated or old cracks have extended inside the rock mass. The direction of the concealed main rupture deduced from the four principal-axis directions of resistivity-changing anisotropy coincide with the strike of fracture belt deduced from GPS displacement measurement of landslip mass (GUO et al, 2004) carried out in March 2003 (Figure 6).

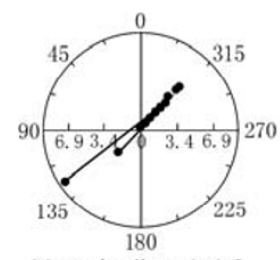

Measuring lines: 1, 4, 3

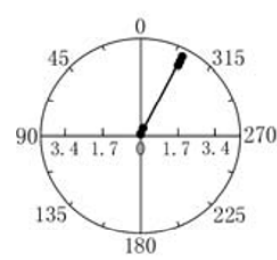

Measuring lines: $1,4,3$
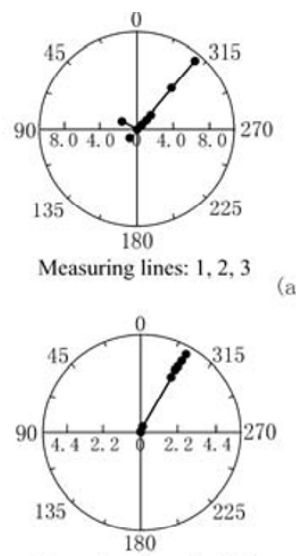

Measuring lines: $1,2,3$

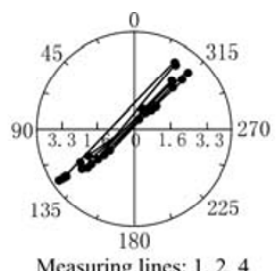

a)

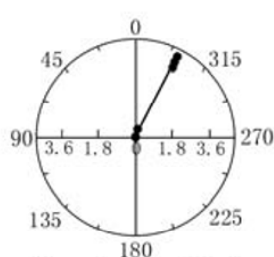

(b)

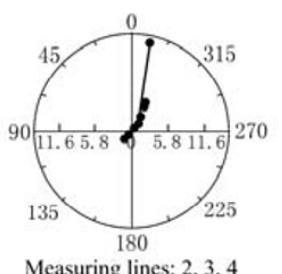

Measuring lines: $2,3,4$

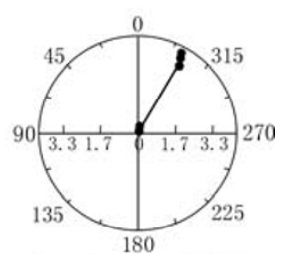

Measuring lines: 2,3,4

Figure 5 Diagram of $\varphi_{1}$ and $\left(\lambda^{*}\right)^{2}$ deduced from combination of measuring points of resistivity-changing anisotropy with small electric polar distance.

(a) Result of arrays with small electric polar distance in the former stage of second section (August 25 to September 25); (b) Result of arrays with small electric polar distance in the former stage of third section (November 10 28)

It is known from the principles of resistivity-changing anisotropy that the magnitude of resistivity-changing anisotropy coefficient reflects the rate for forming resistivity-changing anisotropy, namely, the rate of new cracks concentration or old cracks extension at the measuring point. We can see from Figure 5 that the distributing points of resistivity-changing anisotropy coefficient in the former stage of the second segment have a big jump along the principal-axis direction, while the distributing points of anisotropic coefficient in the former stage of the third segment have almost no change and more than thirty points are concentrated in a small area. It shows that the coefficient change of resistivity-changing anisotropy in the former stage of the second segment is bigger than that in the former stage of the third segment, i.e., the rate of crack change in the sec- 


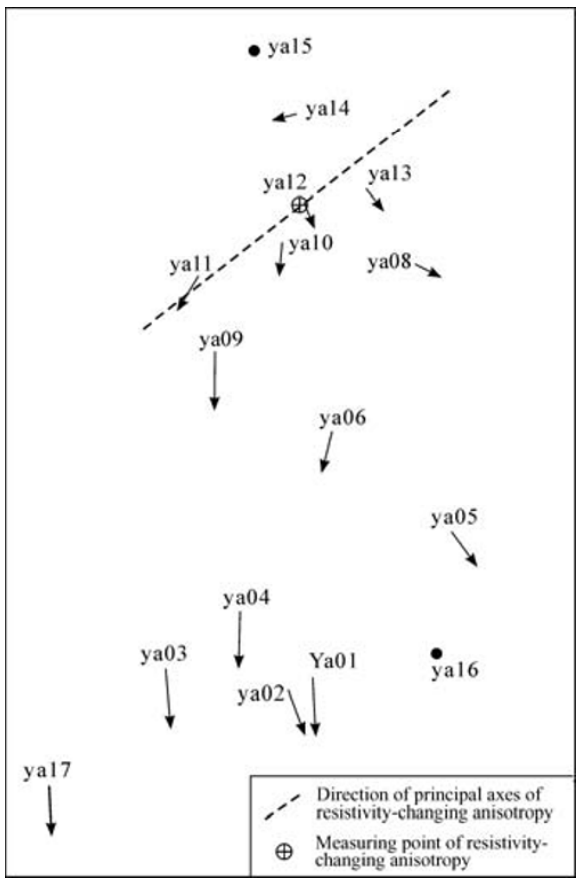

Figure 6 Displacement of GPS stations ond segment is bigger than that in the third segment. Figure $4 \mathrm{~b}$ is a curve diagram of variation of deep displacement of landslip mass measured by suing clinometer in the nearby ZK1 borehole. It is apparent from the curve diagram that the slope of displacement curve is big in the monitoring period of resistivity-changing anisotropy corresponding to the former stage of the second segment, which indicates the rate of displacement change is big; while the slope of displacement curve is quite stable in the monitoring period of resistivity-changing anisotropy corresponding to the former stage of the third segment, which shows that the results measured by two different kinds of monitoring methods correspond to each other in the two corresponding monitoring periods.

The results from large spacing arrays and small spacing arrays are approximately identical, but the four results from large spacing arrays are not as consistent as those from small spacing arrays. The reason may be that the large spacing arrays may reflect not only the change in the area of small spacing arrays, but also the change of cracks in a larger area and a deeper layer. Therefore, it reflects a synthetic change within the exploring area, which might be more complicated.

As to the measuring data used in the paper, some of them are observed in rainy days and some of them in sunny days. Meteorologic change will certainly affect the measured resistivity data of a single array. If a conventional method is used to analyze the resistivity curve shape, it will be very difficult to gain a result. However, meteorologic change could hardly affect the computing results of resistivity-changing anisotropy, which verifies that this method does have the peculiarity to definitely eliminate this kind of interference and can be adopted to meet the need of long-term field monitoring. Moreover, we have also found in the tests that this computing method of resistivity-changing anisotropy is capable to eliminate the effect of false measuring data on the computed results, for it has a function of mutual verification. Namely, when some arrays are damaged, or the measuring instrument and observer makes a mistake, the measured data are not true anymore and the natural relation of data of this array with other arrays is destroyed. However, the calculation program can automatically find the abnormal phenomena in computing resistivity-changing anisotropy and no result will be given, so as to protect the results from the effect of false data and gain true and reliable results.

The tests have also shown that the electrodes and arrays buried in a shallow depth are liable to be disturbed and destroyed by animal, critter and human beings. If the electrodes and arrays are buried deeply, and all connector lugs of electrodes and arrays are fixed in a moisture-proof concrete box on the ground or in a house that can be locked up, we can make the measurement regularly rather than continuously and mobile measurement can be realized in this way. 


\section{Conclusions}

Rock-mass destabilization may give rise to many kinds of geological hazards, which bring about heavy losses to the national economy and property and huge damage to the existence and development of the humankind. Every year, large numbers of people in the world lose their lives in these geologic hazards.

Nowadays, in order to give references to the staff officers for making policies to rebuild and harness latent disastrous areas, block out highly dangerous and risk regions, and reinforce monitoring and forecasting catastrophic locations, simple and convenient, rapid and effective technical means are badly needed to monitor the preparing and developing courses of these hazards. Since deformation behaviors of geologic hazard mass are diverse and complex, the corresponding monitoring means should also have multiple types and more functions.

Using resistivity-changing anisotropy as a means to monitor rock-mass destabilization has the following merits: (1) In exploring mechanism, the method connects directly the resistivity-changing anisotropy due to rock-mass fractures under loading with the conducting path changes of water network due to extending rock-mass cracks, so as to avoid the most complex and difficult problems of state and mode of force loading for rock-mass failure, and the problem of mechanical characteristics of materials. Thus what obtained are the firsthand visible data with definite precursory information that can be used for overall analysis of precursors; (2) In exploring principle, the method is capable to judge the measuring point in the phase of new-cracks concentration or old-cracks extension on the basis of the case whether anisotropy has formed or not in the measured apparent resistivity change of rock mass, so as to catch precursors of rock-mass transition from steady state to non-steady state. It cannot be disturbed by the apparent resistivity change of rock mass in the course of stress adjustment when the rock mass has not entered into the phase of destabilization, because neither micro-crack concentration nor anisotropy of apparent resistivity change will occur in this course; (3) As a kind of scatheless exploration, it can detect the depth of several meters to hundreds meters, which is the most economic means in monitoring the deep change of potential geologic hazard; (4) The method has a certain ability to explore the change of concealed fault activity in the shallow layer; (5) It is capable to make multiparameter integrated exploration with reference to the principal-axis directions of resistivity changing anisotropy, anisotropic rate, and shape, amplitude, and speed of resistivity changes, which has multiple constraint conditions in identifying precursors so as to improve the credibility of precursor identification; (6) It is rapid in setting monitoring points and is capable to carry out periodic or non-periodic mobile measurements, so its expenses for point setting and monitoring are relatively low.

The aforesaid test results have shown that using the method in this paper to explore and monitor hazards of geology and engineering geology is practicable. Further efforts on the method will have a great significance and a better practical prospect for monitoring and forecasting hazards of geology and engineering geology, as well as the research in its mechanism. If a mobile observation station of resistivity-changing anisotropy can be set up in the testing area of earthquake monitoring and mobile measurements can be carried out periodically or non-periodically, it will be significant for studying the precursors of geoelectric resistivity change in the course of earthquake preparation. The method is hopeful to develop into a new monitoring means for both general survey and long-range monitoring for the latent geologic hazard mass. 


\section{References}

AN Jin-zhen, XIU Ji-gang, CHEN Feng, et al. 1997. Study on anisotropy of rock resistivity changes under uniaxal pressure and water replenishment [J]. Earthquake Research in China, 11(1): 77-85.

CHEN Da-yuan, CHEN Feng, HE Guo-yu. 1987. Influences of "stress reversal" on rock resistivity during loading procedure [J]. Acta Seismologica Sinica, 9(3): 303-311 (in Chinese).

CHEN Feng, AN Jin-zhen, LIAO Chun-ting. 2003a. Directional characteristics of resistivity changes in rock of original resistivity anisotropy [J]. Chinese J Geophys, 46(2): 381-395.

CHEN Feng, LIAO Chun-ting, AN Jin-zhen. 2003b. Amplitude and anisotropy of apparent resistivity changing of big models during shear and frictional slipping [J]. Chinese J Geophys, 46(5): 954-965.

CHEN Feng, XIU Ji-gang, AN Jin-zhen, et al. 2000. Research on dependence of resistivity changing anisotropy on microcracks extending in rock with experiment [J]. Acta Seismologica Sinica, 13(3): 331-341.

GUO Jing-jun, YANG Jiu-long, DING Zhi-gang, et al. 2004. GPS application in landslide monitoring: A case study of the Xiakou landslide, Ya'an Sichuan [J]. Journal of Geomechanics, 10(1): 65-70 (in Chinese).

LU Yang-quan, QIAN Jia-dong, LIU Jian-yi. 1988. Resistivity changes in the frictional sliding experiments of sandstone samples and their application in the study of earthquake prediction [J]. Northwestern Seismological Journal, 10(3): 51-56 (in Chinese).

LU Yang-quan, QIAN Jia-dong, LIU Jian-yi. 1990. An experimental study on the precursory features of apparent resistivity and acoustic emission of large scale of granite specimen during the process of slowly dilatancy rupturing [J]. Northwestern Seismological Journal, 12(2): 35-41 (in Chinese).

Polder R B. 2001. Test methods for on site measurement of resistivity of concrete- a RILEM TC- 154 technical recommendation [J]. Construction and Building Materials, 15: 125-131.

QIAN Jia-dong, CHEN You-fa, et al. 1989. Collected Translation Works of Earthquake Geoelectricity [M]. Seismological Press: 3-124 (in Chinese).

Rein A, Hoffmann R, Dietrich P. 2004. Influence of natural time-dependent variations of electrical conductivity on DC resistivity measurements [J]. Journal of Hydrology, 285: 215-232.

Sjödahl P, Dahlin T, Johansson S. 2005. Using resistivity measurements for dam safety evaluation at Enemossen tailings dam in southern Sweden [J]. Environ Geo, 49: 267-273.

TANG Hai-sheng. 1999. The application of direct current resistivity sounding in exploring Baitukan landslide Kangding, Sichuan West Tableland [J]. The Chinese Journal of Geological Hazard and Control, 10(1): 99-104 (in Chinese).

ZHANG Jin-zhu and LU Yang-quan.1983. An experimental study on the variation of rock resistivity under triaxially different stresses [J]. Acta Seismologica Sinica, 5(4): 440-445 (in Chinese).

ZHANG Tian-zhong, HUA Zheng-xing, XU Ming-fa. 1985. Electrical resistivity changes in rock samples during fracture and frictional sliding at 1.2 KB confining pressure [J]. Acta Seismologica Sinica, 7(4): 428-433 (in Chinese).

ZHANG Tong-jun. 1981. Experimental study on the variations in apparent resistivity associated with the stress-strain state of the rock-walls in the underground mine tunnels [J]. Northwestern Seismological Journal, 3(1): 1-24 (in Chinese).

ZHAO Yu-lin, QIAN Fu-ye, YANG Ti-cheng. 1983. Experiments in situ of electrical resistivity changes [J]. Acta Seismologica Sinica, 5(2): 217-225 (in Chinese).

ZOU De-yun, WU Chao, ZHANG Xu-yan, et al. 2003. Feasibility study of the prediction for rock mass destabilization by applying rock mass resistivity [J]. Coal Geology and Exploration, 31(1): 51-54 (in Chinese). 